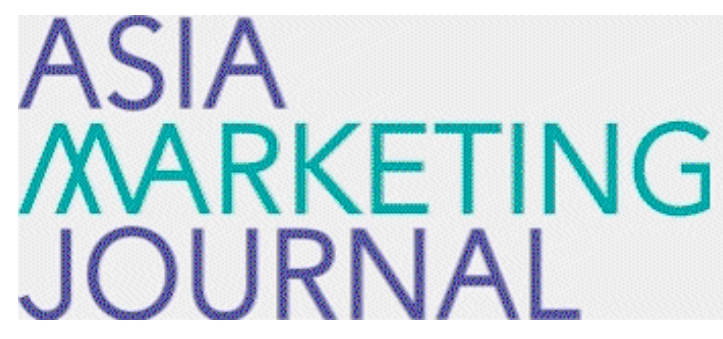

ASIA MARKETING JOURNAL

\title{
The Application of the Goal-Gradient Hypothesis and the Temporal Construal Theory to Customer Loyalty Programs - Goal Gradient Hypothesis and Temporal Construal Theory
}

Tae Ho Song

Wooli Ko

Follow this and additional works at: https://amj.kma.re.kr/journal

Part of the Marketing Commons

\section{Recommended Citation}

Song, Tae Ho and Ko, Wooli (2014) "The Application of the Goal-Gradient Hypothesis and the Temporal Construal Theory to Customer Loyalty Programs - Goal Gradient Hypothesis and Temporal Construal Theory," Asia Marketing Journal: Vol. 16 : Iss. 1 , Article 1.

Available at: https://doi.org/10.53728/2765-6500.1524

This Article is brought to you for free and open access by Asia Marketing Journal. It has been accepted for inclusion in Asia Marketing Journal by an authorized editor of Asia Marketing Journal. 


\title{
The Application of the Goal-Gradient Hypothesis and the Temporal Construal Theory to Customer Loyalty Programs - Goal Gradient Hypothesis and Temporal Construal Theory*
}

\author{
Tae Ho Song** \\ Mincheol Kim*** \\ Wooli $\mathrm{Ko}^{* * * *}$
}

The goal-gradient hypothesis states that the tendency to approach a goal increases with the increasing proximity of the goal (Hull 1932). It was initially supported with an evidence of animal experiments and since then, several papers have investigated the goal-gradient hypothesis in humans. Although there are some evidences related to the goal-gradient hypothesis in human behaviors, none of previous studies can properly explain its underlying mechanism, and what's more, they were not able to suggest useful managerial applications in human behaviors. From these perspectives, this work points out that there are some theoretical weaknesses to apply the goal-gradient hypothesis into the complicated human decision-making behaviors and proposes an alternative theoretical mechanism that underlies the goal-gradient hypothesis in human. Finally, it offers insights into managerial implications of the goal-gradient hypothesis in the marketing field.

This study focuses on the changes in motivations for achieving goals, in terms of how approaches to goals vary according to temporal distance from those goals. Specifically, the temporal construal theory (Liberman and Trope 1998) is considered as the underlying mechanism of the goal-gradient in that the temporal construal theory argues how the temporal distance from a goal makes people change their associated values regarding to that goal. According to the temporal construal theory, the value of distant future outcomes (near future outcomes) is construed on the basis of abstract and central features (concrete and peripheral features), and it argues that distant future situations are construed on a higher level than near future situations. This means that the value associated with the high-level construal is enhanced over delay, whereas the value associated with the low-level construal is discounted over delay. Our propositions suggest that the goal-gradient behavior in human can be motivated by the different aspects or characteristics of the goal as time changes based on the temporal construal theory. Thus, the following propositions are proposed.

\footnotetext{
* This work was supported by Pusan National Univeristy Research Grant, 2012

** Assistant Professor of Marketing, Pusan National University, School of Business(thsong@pusan.ac.kr)

*** Ph.D. candidate, Korea University, Business School(gabriel_kim@korea.ac.kr)

**** Ph.D. student, Korea University, Business School(ghabegi@korea.ac.kr), Corresponding Author
} 
P 1-1: If the goal is far away, consumers put more value on the central features that are more associated with the desirability of the goal.

P 1-2: If the goal is far away, consumers put more effort into accomplishing the goal that has more central features, regardless of its peripheral features.

P 2-1: If a goal is near, consumers put more value on the peripheral features that are more associated with the feasibility of the goal.

P 2-2: If a goal is near, consumers put more effort into accomplishing the goal that has more peripheral features, regardless of its central features.

We hope to provide sufficient managerial implications for the companies as our research aims to show how consumers react differently as they progress toward the goal. Proposed propositions may provide guidance for companies developing a loyalty program, enabling them to understand what kinds of benefits or services they should provide or emphasize to consumers in loyalty programs on the basis of the time-dependent changes in outcome values (such as gifts, reward coupons). The effects of temporal distance from a goal should inform companies' marketing activities and help them to determine where emphasis should be placed in designing the benefits of their loyalty program.

Key words: Goal-gradient hypothesis, temporal construal theory, goal, motivation, loyalty program

\section{Introduction}

Hull (1932) proposed the goal-gradient hypothesis which states that the tendency to approach a goal increases with the increasing proximity of the goal. He supported this theory with animal experiments in which he proved that the speed at which rats run toward food gets faster as they get closer to the goal. Since then, a number of papers have investigated the goal-gradient hypothesis in both animals and humans areas, but the goal-gradient theory in human behavior was not given much attention in the application of marketing field until Kivetz et al. (2006) and Nunes and Dreze (2006) proved in their studies.

Although there is support for the application of the goal-gradient hypothesis to human behaviors, we are not sure of the underlying mechanisms of this theory. Previous studies assumed that the motivation of both animals and humans to accomplish a goal increases as they get closer to the goal, but there has been no supporting analysis for this relationship, so this assumption cannot be credible. Furthermore, these studies have not properly explained the underlying mechanism of related issues that may influence the changes in motivation level as the subjects get closer to the goals. 
Several papers showed that people's values and motivations get changed as the distance from the final goal changes. For example, Liberman and Trope (1998) introduced the temporal construal theory, which argues that the temporal distance from a goal makes people change their associated values regarding to that goal. Additionally, they distinguished value-associated features linked to the temporal distance from the goal into the enhanced features over delays and discounted features associated with delays, thus offering theoretical support for expected changes in people's motivation to reach a goal.

In this study, we will apply the temporal construal theory to examine the underlying mechanism of the goal-gradient hypothesis. Both this theory and the goal-gradient hypothesis involve future events; they involve starting far from those events and getting closer to them as the event progresses. By these means, we hope to develop the goal-gradient hypothesis by providing more logical explanations for it, and clarifying the relevant managerial implications for practitioners.

\section{Theoretical Background}

Hull (1934) supported the goal-gradient hypothesis with his experiments in which rabbits running toward food were found to run faster as they got close to their goals. Figure 1 shows
Hull's (1934) experimental results. In a later study, Brown (1948) attached rats to an apparatus and compared the force in grams with which the rats pulled when they stopped near food versus that when they were at a distance from it. Consistent with the goal-gradient hypothesis, he recorded a greater force when rats stopped close to the food than when they were far away. Although the goal-gradient hypothesis has been studied extensively with animals (Hull 1934; Brown 1948), its implications have received much less attention in human behavior (Kivetz et al. 2006).

〈Figure 1〉 Typical Findings from Hull's( 1934) Experiments with Rats

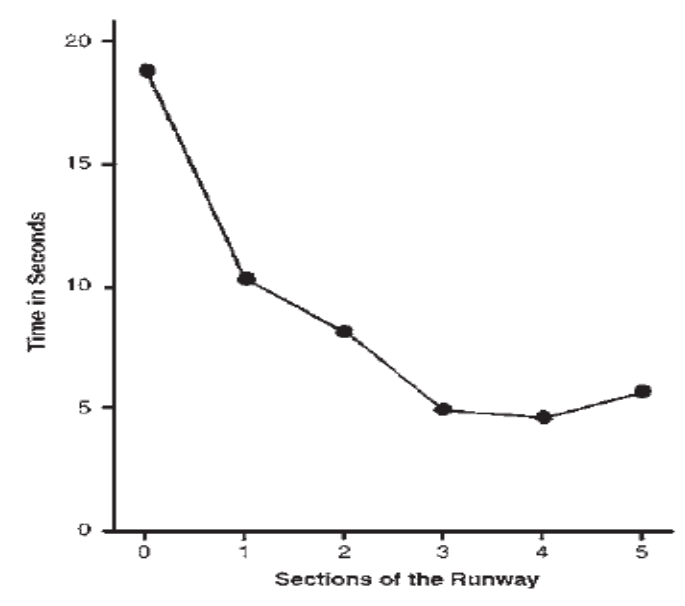

Although several papers have investigated the goal-gradient hypothesis in humans areas (Fajans 1933; Meade and Peterson (1960), the goal-gradient theory in human behavior was not given much attention in the application of 
marketing field. Recent works done by Kivetz et al. (2006) and Nunes and Dreze (2006) investigated the possibility of applying the goalgradient hypothesis in the marketing field. Their studies showed that the goal-gradient hypothesis can explain human behaviors such as humans increased tendency to approach a goal with the increasing proximity of the goal. Figures 2 and 3 show the results of a study by Kivetz, Urminsky, and Zheng (2006), while Figure 4 depicts the findings of Nunes and Dreze (2006). Their results differ little from those of Hull's (1934) experiments with animals.

While Kivetz, Urminsky, and Zheng's (2006) study focused on the causes behind the goalgradient hypothesis, Nunes and Dreze's work (2006) suggested an endowed progress effect and explained that the goal-gradient hypothesis can be one of the possible reasons for this effect. The endowed progress effect explains how people's motivation to pursue a goal gets stronger when there is an artificial advancement. For example, when people receive a coupon that requires ten stamps to get a free coffee, and the coupon has two complementary stamps already affixed, their motivation to get a free coffee increases as the distance from the goal lessens. Nunes and Dreze (2006) said that the causes of endowed progress effect can be explained by the status quo (Inertia) effect or the goal-gradient hypothesis and there are no sunk cost effects.

Though previous studies imply that the goalgradient hypothesis can be applied to both
〈Figure 2〉 Purchase accelerations as a function of smaller goal distance

(Kivetz, Urminsky and Zheng, 2006)

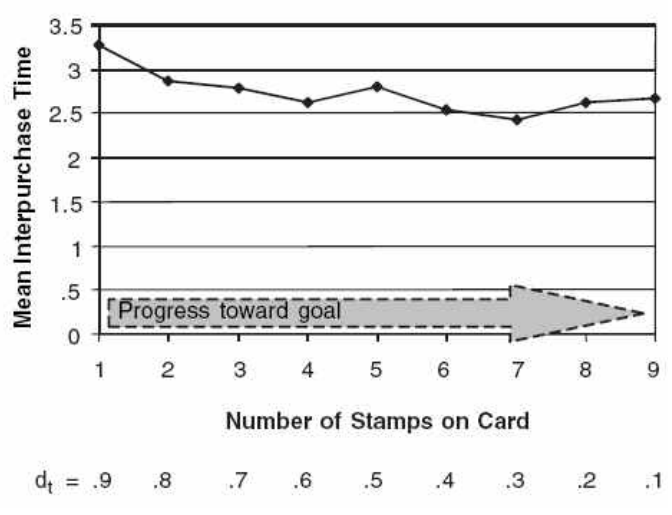

〈Figure 3〉 Average inter-purchase times on first and second cards(Kivetz, Urminsky and Zheng, 2006)

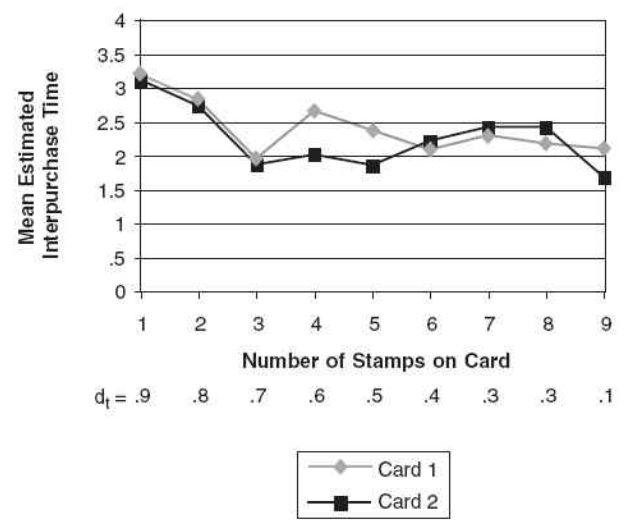

〈Figure 4〉 Car Wash Visits (Nunes and Dreze, 2006)

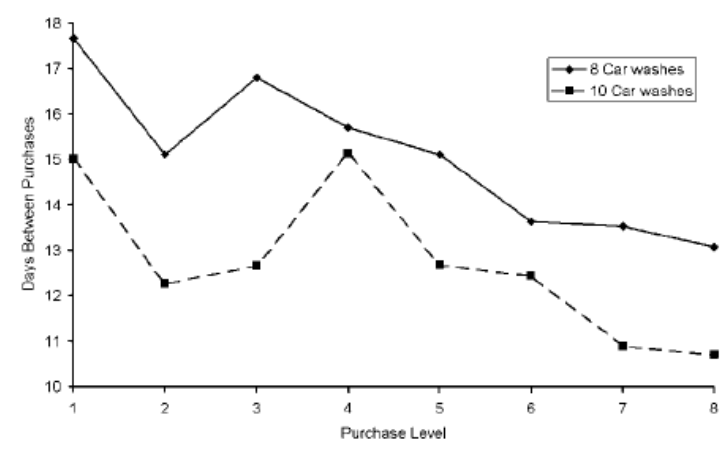


animal and human behaviors (Nunes and Dreze, 2006; Kivetz et al., 2006), we suggest that simply taking the mechanisms behind the goalgradient hypothesis in animals and extending them to humans is an insufficient means of explaining complicated human decision-making behaviors. Kivetz, Urminsky, and Zheng (2006) assumed that the goal-gradient hypothesis in human behaviors can be explained by habituation, heterogeneity, time discount, sunk cost, and psychological distance from the goal. To test these five underlying causes of the goal-gradient hypothesis, they devised field study experiments. Their results showed that only the perception of the original distance from a goal explains the goal-gradient hypothesis, whereas the other four causes do not. Nunes and Dreze (2006) showed similar results in their studies.

The goal-gradient hypothesis tries to explain situational changes in human behaviors as they approach the goal, so we can assume that the goal-gradient hypothesis is closely linked to the studies related to time-dependent change. In the studies related to time-dependent change, the value associated with features or preferences changes with the temporal distance from the goal such as near or far, and several papers have examined these phenomena in the context of different applications. The key assumption in the studies related time-dependent change is that the value of the outcome is discounted or diminished over a period of delay (Liberman and Trope, 1998). Although many previous studies support this assumption (Ainslie and Haslam, 1992: Mischel, Shod, and Rodriguez, 1989), several have shown reversal effects, in which the value of the outcome is actually enhanced over a period of delay (Elster and Loewenstein, 1992; Loewenstein, 1987).

Though time-dependent change in the value of discounting reversal can be explained by conflict models, delay of gratification, and selfcontrol theory, these assumptions are inadequate to explain the mechanisms that may underlie time-dependent changes. In addition, timedependent changes in the expectancies of reversal outcomes can be explained by cold feet (i.e. individuals have higher performance $\mathrm{ex}^{-}$ pectations for the distant future than for the near future) (Gilovich et al., 1993), and planning fallacy, (i.e. individuals underestimate task completion times) (Buhler et al., 1994), but these issues are also limited in classifying the underlying mechanism of time-dependent changes. Liberman and Trope (1998) introduced the temporal construal theory, which classifies types of discounted outcome values and augmented outcome values in time-dependent changes. The temporal construal theory states that people tend to use high-level construal in construing distant future goals, whereas they use more lowlevel construal in construing near future goals. Indeed, the value associated with the high-level construal decreases over time while the value associated with the low-level construal increases over time. By using Vallacher and Wegner's 
(1989) level of personal agency questionnaire, Liberman and Trope (1998) measured high-level construal for distant future goals and low-level construal for near future goals. Their results supported the temporal construal theory as they proved that distant future goals were construed on the basis of higher-level features, whereas near future goals were construed using lower-level features than those used for distant future goals.

Bagozzi and Dholakia (1999) argued that both desirability and feasibility values are associated in a single goal. Desirability refers to the value or valence of the end state of a goal whereas feasibility refers to the expectancy of reaching the end state of a goal. Thus, desirability corresponds to high-level construal with more central features whereas feasibility corresponds to low-level construal with more peripheral features. Along with this, if we apply the action identification theory (Vallacher and Wegner 1987), desirability meets superordinate and central features as it indicates why the action is done and feasibility meets subordinate and specific features of the goal achievement. To assess time-dependent changes in these values, Liberman and Trope (1998) also compared a choice of high desirability with a choice of high feasibility in both the distant future and the near future in their studies. The results again supported their theory by showing that people put relatively more value on the higher feasibility option when looking at the near future and on the higher desirability option when looking at the distant future. This inversion of preference can be seen as resulting from the influence of desirability and feasibility considerations, which implies that the temporal construal theory can support the underlying mechanism of temporal distance effects.

\section{Propositions}

According to the temporal construal theory, the value of distant future outcomes is construed on the basis of abstract and central features. Essentially, the temporal construal theory suggests that distant future situations are construed on a higher level than near future situations. This means that the value associated with the high-level construal is enhanced over delay, whereas the value associated with the low-level construal is discounted over delay (Liberman and Trope 1998). In this study, we concentrate on the time-discounting and the time-augmenting characteristics of the temporal construal theory since the current study's stimulus, "Goal”, accounts both high-level and low-level construal with the same importance.

If the future goal is far away, the goal-gradient hypothesis applies a similar value associated with the future goal as that applied by the temporal construal theory in a distant future situation. Thus, if a distant goal is con- 
strued on the basis of features with central meanings, consumers' motivation to achieve the goal increases, and, in turn, they will put more effort to achieve it.

P 1-1: If the goal is far away, consumers put more value on the central features that are more associated with the desirability of the goal.

In the achievement of motivation, expectancy is one of the fundamental elements which affect motivation (Atkinson 1957). Expectancy is a function of perceived value and the likelihood of success from expectancy-value model (Klein 1991). Therefore, higher (perceived) valuation can create higher motivation to achieve the goal, but since the underlying motivation is hard to observe, we regard the efforts as motivation and we propose the following proposition.

P 1-2: If the goal is far away, consumers put more effort into accomplishing the goal that has more central features, regardless of its peripheral features.

On the other hand, the values of near future events are likely to be more concrete and focus on the peripheral features. If a goal is near, the goal-gradient hypothesis applies a similar value associated with the goal as that applied by the temporal construal theory to a near future situation. Thus, if a near future goal is construed on the basis of the features of peripheral meanings, consumers' motivation to reach the goal increases, and, in turn, they will put more effort to achieve that goal.

P 2-1: If a goal is near, consumers put more value on the peripheral features that are more associated with the feasibility of the goal.

$\mathrm{P} 2$ 2-2: If a goal is near, consumers put more effort into accomplishing the goal that has more peripheral features, regardless of its central features.

〈Figure 5〉 Descriptive Explanation of Propositions

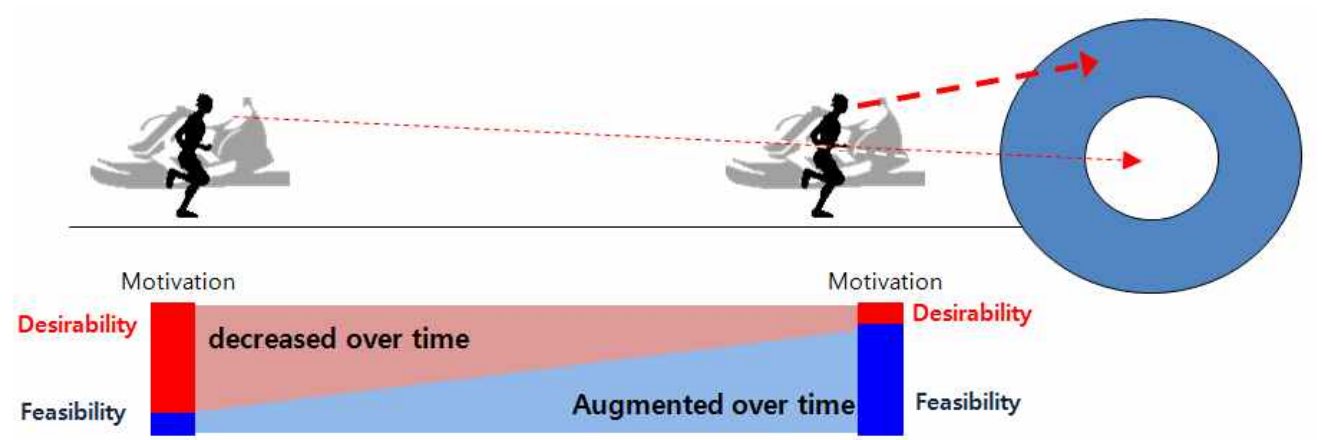

The Application of the Goal-Gradient Hypothesis and the Temporal Construal Theory to Customer Loyalty Programs 7 
Figure 5 illustrates our propositions. As mentioned in the previous section, desirability is mainly associated with the central features related to high-level construal, whereas feasibility is mainly associated with the peripheral features related to low-level construal. Based on these arguments, we consider desirability a central feature and feasibility a peripheral feature. In Figure 5, a person runs from the left to the right, and the left side implies a distant situation from the goal, so that as the person runs toward the right, the person gets closer to the goal. In this situation, a person at the left side (far away from the goal) focuses on the center of the target, but as the person moves to the right, this person looks at the side of the target, meaning its peripheral features. According to the temporal construal theory, even the goalgradient phenomenon occurs in both of the distance and near future goals, the reasons for the motivations and the efforts made to accomplish a goal vary depending temporal circumstances. The influence of desirability is stronger when a goal is in the distant future, whereas the influence of feasibility is stronger when a goal is in the near future.

\section{Implications and Limitations}

The goal-gradient hypothesis can be understood as an intuitive human behavior, and we can easily notice this phenomenon in our daily lives. Despite its common occurrence, the goalgradient hypothesis in human behaviors has not been studied much. Kivetz, Urminsky, and Zheng (2006) and Nunes and Dreze (2006) have proven that the goal-gradient hypothesis can apply to human behaviors, but do not address the general mechanisms that may underlie the goal-gradient hypothesis at the lower levels of related processes. Our current study develops the goal-gradient hypothesis in more detail by suggesting a general mechanism that underlies the progress of the goal-gradient hypothesis.

In our study, we focus on the changes in motivations for achieving goals, in terms of how approaches to goals vary according to temporal distance from those goals. Thus, we proposed the temporal construal theory as an underlying mechanism of the goal-gradient hypothesis. According to the temporal construal theory (Liberman and Trope 1998), more value is put on features that are central to the meaning of the outcome in distant future situations, whereas in near future situations, more value is put on the peripheral features of the outcome. We can thus apply this theory as an underlying mechanism to explain the goal-gradient hypothesis.

In practice, it is not surprising that many companies run loyalty programs as part of their promotional activities, because these programs not only encourage repeat purchases but also prevent customers from being lost to competitors. 
Traditionally, only a limited range of companies, such as coffee shops or gas stations, used loyalty programs involving punch cards, coupons, or stamps to increase customer retention. Today, more companies from different industries, such as the airline, credit card, grocery, and bookselling industries, are using loyalty programs, and they are making them easier to access with smartphone applications and plastic barcode tags.

Many research papers have proved the effectiveness of loyalty programs from different angles (Kim et al., 2012; Yi and Jeon, 2003). However, these studies have not explained consumers' point redemption behaviors (Tayler and Neslin, 2005) and the optimal loyalty program progress, with regard to factors such as temporal distance from the reward.

In the current study, we considered how motivation preferences develop as consumers progress toward the goal from distant to near, by analyzing consumers' consumption behaviors. We explained how different types of value associations are involved in progress toward goal accomplishment by applying the temporal construal theory. We hope to provide adequate managerial implications for companies as our research aims to show how consumers react differently as they progress toward the goal, including (1) how consumers' preferred features differ in relation to desirability and feasibility, (2) how motivation changes the value of a goal, and (3) how the level of motivation to achieve a goal differs with the types of goal.

If a goal is far, consumers focus relatively more on abstract, primary, decontextualized, and goal-relevant features, meaning their motivations to accomplish the goal are more in line with the central meaning of the goal. This means that when marketers choose to offer consumers gifts or develop marketing activities like advertisements and public relations, they should focus on the central features of the goal in such a condition. On the other hand, if a goal is near, consumers focus relatively more on concrete, surface, secondary, contextualized, and goal-irrelevant features, meaning that their motivation to accomplish the goal is more in line with the peripheral features. Thus, to maximize the effectiveness of marketing activities such as giving out samples or engaging advertisements and promotions, marketers should focus on peripheral and incidental features rather than on the central features of the goal in such a condition (Trope and Liberman, 2003).

As an example, we can assume there is a coffee shop that sells fair trade coffee tries to create a new loyalty program and promote it. The purpose of the loyalty program is to increase steady sales rates through memberships. For customers who become members, the company could offer the benefit (goal) of gaining a free coffee by collecting 10 stamps through purchases (one stamp per cup of coffee purchased), or it could donate money from each purchase to pay for the schooling expenses of 
disadvantaged African children. If such a coffee shop wants to increase consumer retention rates, it should run sequential advertisements instead of one steady advertisement. For example, in the early phases of the advertisement, it should focus on a message such as "buying fair trade coffee gives African children a dream. As the goal gets closer, the company should change the advertisement to "buying fair trade coffee educates the Kaldy of Ethiopia” (Kim et al. 2012). The former advertisement accounts for desirability by targeting the value of an end state (a superordinate or high-level construal), whereas the latter advertisement accounts for feasibility by targeting how the end state can be achieved (a subordinate or low-level construal).

In short, we expect that the results of our study will provide guidance for developing loyalty programs. On the basis of time-dependent changes in outcome value, companies can determine what kinds of benefits or services they should provide to the consumers in loyalty programs. The effects of temporal distance from a goal should inform companies' advertising and communication activities and help them to determine where emphasis should be placed in designing the benefits of their loyalty program.

There are several limitations to our study. First, as a research note, we have not addressed any experiential analysis. Our study logically developed the underlying mechanism of the goal-gradient hypothesis and provided new insights into this hypothesis, both academically and practically, but there is no experimental analysis to support our theory. However, we can overcome this limitation through further development of our study with experimental testing and data analysis.

As we only consider the occurrence of the goal-gradient hypothesis situation in our study, our propositions cannot explain a situation with no goal-gradient hypothesis. For example, when consumers are very close to reaching a goal, there are some situations in which they stop making an effort to progress. Our propositions cannot explain this phenomenon. Furthermore, unlike the traditional goal-gradient hypothesis, there are some situations in which consumers' motivation starts to decrease from the moment progress commences. Once again, this phenomenon cannot be explained by the goal-gradient hypothesis.

The focus of the current study is on acceleration in the goal-gradient hypothesis. In other words, our propositions assume that everyone accomplishes their goal. However, persistency also plays an important role in the goalgradient hypothesis. Thus, in the future research, we can further study the underlying mechanism of persistency and examine the relationship between acceleration and persistency in the goal-gradient hypothesis.

Finally, there may be various moderating factors that can affect the relationship between the efforts and the temporal distance from the 
goal. For example, Kim (2014) considered the regulatory focus as a moderating variable that can affect in consumer's redemption behavior. Thus, we can investigate an interaction effect between the temporal construal and the regulatory focus on the goal-gradient consumer behavior in the future research.

〈Received April 29. 2013〉

〈1st Revised September 30. 2013〉

〈2nd Revised December 11. 2013〉

〈Accepted January 22. 2014〉

\section{References}

Ainslie, G., and Haslam, N. (1992), Hyperbolic discounting. In G.Loewnestein \& J. Elster (Eds.), Choice over time (pp. 57-92). New York: Russell Stage Foundation.

Atkinson, John W. (1957), "Motivational Determinants of Risk-Taking Behavior," $P_{S y^{-}}$ chological Review, 64 (November), 359-72. Baggozzi, Richard P., and Dolakia, Utpal (1999), "Goal Setting an Goal striving in Consumer Behavior," Journal of Marketing, 63(4), 19-32

Brown, Judson S. (1948), "Gradients of Approach and Avoidance Responses and Their Relation to Level of Motivation," Journal of Comparative and Physilkklological Psychology, 41 (6), 450-65.

Buhler, R., Griffin, D., and Ross, M. (1994),
"Exploring the "Planning Fallacy": Why People Underestimate their task completion times," Journal of Personality and Social Psychology, 67, 366-381

Elster, J., abd Loewenstein, G. (1992). Utility from memory and anticipation. In $G$. Koewenstein \& J. Elster (Eds), Choice over time (pp.213-234). New York: Russell Sage foundation.

Gilovich, T., Kerr, M., and Medvec, V.H. (1993), "Effect of Temporal Perspective on Subjective Confidence," Journal of Personality and Social Psychology, 64, 552-560

Hull, Clark L. (1932), "The Goal-Gradient Hypothesis and Maze Learning," Psychological Review, 39 (1), 25-43. (1934), "The Rats' Speed of Locomotion Gradient in the Approach to Food," Journal of Comparative Psychology, 17 (3), 393-422.

Kim, Jae Hwi, Kim, Hee Yeon, and Boo, Su Hyun(2012), "Communication through social media focus on prosocial behavior : The effect of message framing and social distance towards media," The Korean Journal of Advertising, 23(1), 183-205.

Kim, Jiyoon, Lee, Janghyuk, Kim, Sang Yong, Lee, and Bang, Hyung (2012), "The Effects of Point Accumulation Effort Level on Redemption Behavior in Loyalty Program," Korea Marketing Review, 27(1), 85-106.

Kim, Ji Yoon (2014), “The Effect of Regulatory Focus on the Link Between Purchase 
Behavior and Redemption Behavior," Asia Marketing Journal, 15(4), 51-60.

Kivetz, Ran, Urminsky, Oleg, and Zheng, Yuhuang (2006), "The Goal-Gradient Hypothesis Resurrected: Purchase Acceleration, Illusionary Goal Progress, and Customer Retention," Journal of Marketing Research, (Feb), 3958.

Klein, Howard J. (1991), "Further Evidence on the Relationship between Goal-Setting and Expectancy Theory," Organizational Behavior and Human Decision Processes, 49 (2), 23057.

Liberman, Nira and Trope, Yaacov (1998), "The Role of Feasibility and Desirability Considerations in Near and Distant Future Decisions: A Test of Temporal Construal Theory," Journal of Personality and Social Psychology, 75, 5-18.

Loewenstein, George (1987), “Anticipation and the valuation of delayed consumption," The Economic Journal, 97(387), 666-684.

Mischel, W., Shoda, Y., and Rodriguez, M.L. (1989), "Delay of gratification in children," Science, 244(May), 933-938.

Nunes, Joseph C. and Dreze, Xavier (2006), "The Endowed Progress Effect: How Artificial Advancement Increases Effort,"
Journal of Consumer Research, 32 (Mar), 504-512

Vallacher, R. R., and Wegner, D. M. (1987), "What Do People Think They're Doing? Action Identification and Human Behavior," Psychological Review, 94(1), 3-15.

Vallacher, R. R., \& Wegner, D. M. (1989), "Levels of personal agency : Individual variation in action identification," Journal of Personality and Social Psychology, 57, 660-671.

Taylor, G.A. and Neslin, S.A. (2005), "The Current and Future Sales Impact of a Retail Frequency Reward Program," Journal of Retailing, 81(4), 293-305.

Trope, Yaacov and Liberman, Nira(2000), "Temporal Construal and Time-Dependent Changes in Preference," Journal of Personality and Social Psychology, 79(6), pp.876-889.

Trope, Yaacov and Liberman, Nira (2003), "Temporal Construal," Psychological Review, 110 (3), 403-421

Yi, Youjae and Jeon, Hoseong (2003), "Effects of Loyalty Programs on Value Perception, Program Loyalty, and Brand Loyalty," Journal of the Academy of Marketing Science, 31(3), 229-240. 